\title{
Etiology of Head Injuries in Southwestern Nigeria: A Public Health Perspective
}

\author{
A Adeolu, A Malomo, M Shokunbi, E Komolafe, T Abiona
}

\begin{abstract}
Citation
A Adeolu, A Malomo, M Shokunbi, E Komolafe, T Abiona. Etiology of Head Injuries in Southwestern Nigeria: A Public Health Perspective. The Internet Journal of Epidemiology. 2004 Volume 2 Number 2.
\end{abstract}

DOI: $\underline{10.5580 / 21 \mathrm{~d} 2}$

\begin{abstract}
Background and Objective: To effectively carry out appropriate prevention programme for head injury there must be adequate epidemiological data. This is currently scarce in many developing countries including Nigeria. This study was designed to determine the etiology of head injury among patients presenting in our hospital between July 1993 and June 1998 . We also determined the relationship between age of patients and the etiology of head injury.
\end{abstract}

Methodology: We obtained demographic data and etiology of wounding in all patients who presented with head injury in our accident and emergency room. These were obtained from the admission records. Simple statistical analysis was subsequently done.

Results: We reviewed 1130 patients over the study period. Passenger motor vehicular accident was the leading cause (65.3\%) of head injury in our patients. This was followed by fall (16.4\%). Pedestrian motor vehicular accident and fall were more likely to cause head injury in pediatric patients compared to adult patients.

Conclusion: Our findings suggest that the preventive measures that have been used to reduce the incidence and impacts of head injury in other parts of the world can be applied to our community. The high incidence of fall and pedestrian motor vehicular accidents in pediatric age groups suggests negligence and lack of supervision of the underage.

\section{INTRODUCTION}

Trauma is a preventable epidemic neglected by many governments especially in developing countries. Many of the devastating effects of trauma are often from head injuries. ${ }_{1}, 2$ Head injury does not only bring the level of physical and mental health of the community down, especially among the younger age group, but also is a cause of increased socioeconomic burden. The incidence and effects of trauma have been significantly reduced with successful implementation of appropriate health programmes in developed countries like "think first" in the United States..$_{2}$ To effectively carry out appropriate prevention programmes there must be adequate epidemiological data. This is currently lacking in many developing countries including Nigeria.

The present study was designed to determine the etiology of head Injury among patients presenting at our accident and emergency department between July 1993 and June 1998. The specific objectives of the study were:

- To determine the age distribution of patients presenting with head injuries (HI) at our center during the study period.

- To ascertain the common etiologies of HI among the study group.

- To identify any relationship between age of the patients and etiology of HI.

\section{MATERIALS AND METHOD}

This was a retrospective study of all the patients who presented with head injury at the emergency room of our hospital between July 1993 to June 1998. Our center was the main referral hospital for head injury in southwestern 
Nigeria during the study period. The demographic data and the etiologies of head injury were obtained from the admission records of the patients. The data was then subjected to statistical analysis. Cross tabulation was done between the age of the patients and the various etiological agents.

\section{RESULTS}

There were 1541 patients with head injuries over the study period. Specific age was not available for 118 patients. The etiologic factor was not certain in 291 patients. These were excluded from the final analysis. Thus, 1130 patients were analysed. The age range was from 6 months to 88 years. The mean age was 26.7 ( \pm 17.4$)$. Head injuries occurred most frequently at the age of 30 years among our patients.

Most of the injuries occurred in the first three decades of live.

The most common cause of head injury in our series was motor vehicular accidents (MVA) and these accounted for seventy three point four percent. Table 1 further summarises the findings.

\section{Figure 1}

Table 1: Aetiology of injury

\begin{tabular}{lc} 
Aetiologv & Number of Patients (\%) \\
\hline Passenger MVA & $738(65.3)$ \\
Fall & $185(16.4)$ \\
Pedestrian MVA & $91(8.1)$ \\
Assault & $58(5.1)$ \\
Gun shot & $36(3.2)$ \\
Battery & $19(1.7)$ \\
Sport Injuries & $2(0.2)$ \\
Occupational Hazard & $1(0.1)$ \\
\hline Total & 1130
\end{tabular}

Pedestrian MVA was more likely to cause head injury in the first 2 decades of life compared to other age groups ( $p$ value $=0.004$ ). Also, fall was more likely to cause head injury in the first decade of life compared to other age groups ( $\mathrm{p}$ value $<0.001)$. See tables 2-4 for more details.

\section{Figure 2}

Table 2: Age group-aetiology cross tabulation

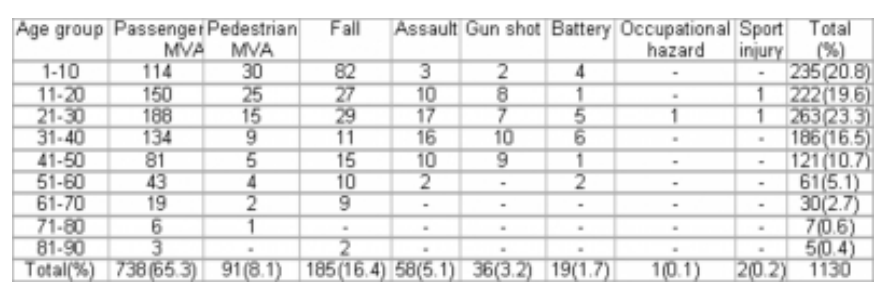

\section{Figure 3}

Table 3: Relationship between age and fall as a cause of head injury

Age group Number of patients with fall Number of patients without fall Total

(\%)

(\%)

\begin{tabular}{llcl}
$1-10$ & $82(34.9)$ & $153(65.1)$ & 235 \\
$11-20$ & $27(12.2)$ & $195(87.8)$ & 222 \\
$21-30$ & $29(11.0)$ & $234(89.0)$ & 263 \\
$31-40$ & $11(5.9)$ & $175(94.1)$ & 186 \\
$41-50$ & $15(12.4)$ & $106(87.6)$ & 121 \\
$>50$ & $21(20.4)$ & $82(76.6)$ & 103 \\
\hline Total & 185 & 945 & 1130
\end{tabular}

$x^{2}=84.712, d f=5, p<0.001$

\section{Figure 4}

Table 4: Relationship between age group and pedestrian MVA (peMVA)

\begin{tabular}{lccr} 
Age group & $\begin{array}{c}\text { Number of patients } \\
\text { with peMVA (\%) }\end{array}$ & $\begin{array}{c}\text { Number of patients } \\
\text { without peMVA(\%) }\end{array}$ & Total \\
$1-10$ & $30(12.8)$ & $205(87.2)$ & 235 \\
$11-20$ & $25(11.3)$ & $197(88.7)$ & 222 \\
$21-30$ & $15(5.7)$ & $288(94.3)$ & 263 \\
$31-40$ & $9(4.9)$ & $177(95.1)$ & 186 \\
$41-50$ & $5(4.3)$ & $116(95.8)$ & 121 \\
$>50$ & $7(6.8)$ & $96(93.2)$ & 103 \\
\hline Total & 91 & 1039 & 1130
\end{tabular}

$x^{2}=17,423$, df: $5, P=0.004$

\section{DISCUSSION}

Motor vehicular accident (MVA) is the most common cause of head injury worldwide. ${ }_{3,4,5,6}$ This is the same among our patients. The increasing use of motor vehicles as means of transport is of immense advantage. However, this can be associated with significant problems especially if appropriate safety precautions are neglected. Poor conditions of the vehicles, neglect of safety measures like the use of seat belts, poor knowledge and/or disregard for traffic rules are potential factors that contribute to accidents particularly in developing countries like Nigeria. Motorcycle passengers often do not wear helmets.

The high incidence of pedestrian and fall in paediatric age group is a call for concern. This finding is similar to previous finding of Shokunbi and Olurin as well as Igun et 
al $_{.7},{ }_{8}$ It denotes negligence and poor supervision of the younger ones by responsible adults. Under aged individuals should not be left unattended.

Sports related injuries are rare in our series. Sporadic communal clashes often account for most of the gun shot injuries. Accidental gun shot injuries including gun burner recoil occur also sporadically. The latter has been previously reported from our environment. 9

Appropriate preventive measures will help to reduce the frequency of head injury in our community. This study demonstrates that head injury is mostly caused by preventable causes in our environment. Appropriate laws should be enacted to enforce wearing of seat belts in vehicles and motorcyclists to use well fitting helmets. Over crowding should be avoided in vehicles. Drivers should be reminded to check their breaks regularly. Worn tyres, especially used imported ones, should be discouraged. Public health campaign akin to programmes like "Think First" in the USA should be encouraged by both government and Non Governmental Organizations. Australia is another example of a country where coordinated efforts at state and national government levels have resulted in significant public health triumphs as regards neurotrauma. ${ }_{10}$ The federal road safety corp of Nigeria is an effort in the right direction but should be made to be more functional and effective.

In this study, we have tried to describe the various causes of head injury in our environment. However, much still need to be done to know the true incidence of head injury in our country. There have been few reports on etiology of head injury in various parts of Nigeria ${ }_{{ }_{11},{ }_{12},{ }_{13}}$ Such information will be more accurate and useful if there are well coordinated epidemiologic survey. There is also the need for national trauma registry or banks where information related to trauma can be easily accessed. This will be essential for planning and appropriate public health campaign.

\section{CORRESPONDENCE TO}

Adeolu AA, MBChB, FWACS Department of Surgery College of Health Sciences OAU, Ile-Ife e-mail: adeoluaa@yahoo.com

\section{References}

1. Adesunkanmi AR, Oginni LM, Oyelami OA, Badru OS. Road traffic accidents to African children: assessment of severity using the injury severity score (ISS). Injury. 2000;31:225-8.

2. Kelly DF, Becker DP. Advances in management of neurosurgical trauma: USA and Canada. World J. Surg. 2001; 25: 1179-1185.

3. Raja IA, Vohra AH, Ahmed M. Neurotrauma in Pakistan. World J. Surg. 2001; 25: 1230-1237.

4. Ohaegbulam SC. Analysis of 1089 cases of head injury. Afr J Med Med Sci. 1978; 7:23-7.

5. Muyembe VM, Suleman N. Head injuries at a Provincial General Hospital in Kenya. East Afr Med J. 1998 ;75:364-9. 6. Adeloye A, Ssembatya-Lule GC. Aetiological and epidemiological aspects ofacute head injury in Malawi. East Afr Med J. 1997;74:822-8.

7. Shokunbi T, Olurin O. Childhood head injury in Ibadan: causes, neurologic complications and outcome. West Afr J Med. 1994;13:38-42.

8. Igun GO, Ihezue $\mathrm{CH}$, Lily-da-tariah OB, Isamade ES. Perspective on paediatric traumatic brain injury. African Journal of Paediatric Surgery. 2004; 1: 24-28

9. Komolafe EO, Olateju OS, Adeolu AA. Gun burner injury: a peculiar accidental self-inflicted missile head injury. Br J Neurosurg. 2004;18:233-239.

10. 10 Atkinson L, Merry G. Advances in neurotrauma in Australia 1970-2000. World J. Surg.; 25: 1224-1229

11. Elesha SO, Daramola AO. Fatal head injuries: the Lagos University Teaching Hospital experience (1993-1997). Niger Postgrad Med J. 2002; 9:38-42

12. Muhammad I. Management of head injuries at the Abu Hospital, Zaria. East Afr Med J. 1990;67:447-51.

13. Akang EE, Kuti MA, Osunkoya AO et al. Pattern of fatal head injuries in Ibadan -a 10 year review. Med Sci Law. 2002; 42:160-6. 


\section{Author Information}

A.A. Adeolu

Department of Surgery, College of Health Sciences, OAU

A.O. Malomo

Department of Surgery, University College Hospital

\section{M.T. Shokunbi}

Department of Surgery, University College Hospital

\section{E.O. Komolafe}

Department of Surgery, College of Health Sciences, OAU

\section{T.C. Abiona}

Department of Community Health, College of Health Sciences, OAU 